\title{
Setariafaberi Seed HeteroblastyBlueprints Seedling Recruitment: I. Seed Dormancy Heterogeneity at Abscission
}

\author{
K. Jovaag' ${ }^{1}$, J. Dekker,", B. Atchison ${ }^{2}$ \\ ${ }^{1}$ Weed Biology Laboratory, Department of Agronomy, Department of Statistics, Iowa State University, Ames, Iowa, 50011, USA \\ ${ }^{2}$ Weed Biology Laboratory, Department of Agronomy, Iowa State University, Ames, Iowa, 50011, USA
}

\begin{abstract}
Studies were conducted to determine the relationship between weedy Setariafaberi seed dormancy and subsequent behaviors in the soil culminating in seedling recruitment.This is the first in a series of three articles demonstrating weedy Setaria seed dormancy capacity heterogeneity at abscission (seed heteroblasty) provides a "blueprint" for those subsequent behaviours. The objective for this present article was to provide a robust characterization of seed heteroblasty at the time of dispersal for 39 locally adapted S. faberi populations, as influenced by parental genotype (time of embryogenesis) and environment (year, location). The heteroblastic structure of each population was revealed by the germination response to increasing amounts of after-ripening (in "ideal" conditions). The majority of the populations were differentiated from each other; this variation indicated a fine scale adaptation to different local environments. Taken together, the 39 responses represented Setaria's "seed dormancy phenotype space" and revealed three different generalized dormancy patterns. The first pattern, low dormancy populations, had high initial germination in response to low doses of after-ripening. The second, high dormancy populations, had no or low initial germination with little additional response to increased after-ripening. Most populations had the third pattern, intermediate to the others, with low initial germination and increasing germination with increasing after-ripening dose. Germination responses were also used to rank populations based on their dormancy level to facilitate later comparisons with emergence behavior. Heteroblasty at abscission, elucidated herein, is hypothesized to influence subsequent seed fates in the soil, the focus of the next two articles in this series
\end{abstract}

Keywords SeedHeteroblasty, Seed Dormancy, Seed Fate, Seedling Recruitment, Setaria, Seed Dispersal

\section{Introduction}

The relationship between seed dormancy induced by parent Setaria plants at the time of abscission is rationalized herein with subsequent behaviours in the soil and seedling recruitment.Evidence provides strong inferences that heterogeneous dormancy among Setaria seeds at abscission is an important determinant of subsequent behaviours of individuals in the soil leading to the timing of recruitment.

The timing of seedling recruitment of an individual relative to that of neighbour plants is one of the most important determinants in plant community assembly and its consequential composition and structure. The importance of recruitment timing is especially crucial in agricultural habitats characterized by frequent, profound disturbance regimes (e.g tillage, herbicides, harvesting) in which theentireplant community is typically removed on an annual basis.

* Corresponding author:

jdekker@iastate.edu (J. Dekker)

Published online at http://journal.sapub.org/plant

Copyright (C) 2012 Scientific \& Academic Publishing. All Rights Reserved
Knowledge of recruitment timing relative to crop emergence is crucial to weed management, particularly foreffective use of control tactics (e.g. tillage, herbicides).

The first phases of the weedy Setaria plants' life history are therefore of critical importance, especially those temporally expressed traits of seed dormancy, germinability, germination and seedling emergence. Foxtails (Setaria speciesgroup) are one of the worst weed groups interfering with U.S. and world agriculture and land management (Dekker 2003, 2004), and therefore one of the world's most successful colonizing plants. Setariafaberi is a recent invasive to North America, infesting large areas of the U.S. corn belt. S. faberi is an ideal species with which to study seed life history: globally it is nearly identical genetically (Wang et al., 1995).

One important trait is the production and dispersal of heterogeneous seed (Dekker \& Hargrove, 2002; Dekker et al., 1996).Heterogeneity of dormancy among seed from a single parent plant, seed heteroblasty, is one of several types of heteroblastic development of repeating plant units (metamers) during plant ontogeny (Gutterman, 1996; Jones, 1999). This phenomenon has been characterized in other 
plant species (e.g. Xanthium pensylvanicum, Weaver \& Lechowicz, 1983; Chenopodium album, Williams \& Harper, 1965).Systematic, quantitative characterization of heteroblasty among individuals within a locally adapted population, between local populations, and their relationship tosubsequent life history behaviours has not been reported previously.

An individual weedy Setaria spp. plant synflorescence produces individual seeds whose germination requirements vary.This seed heteroblasty occurs in any parental environment, even those within controlled, constant conditions for the duration of its life history (Dekker, et al., 1996; Harr, 1998). Seed heteroblasty is therefore a constitutively expressed genetic (or epigenetic) trait.The dormancy capacity of a individual S. faberi seed refers to its dormancy state at abscission, as well as the quantity of environmental signals (oxy-hydro-thermal time; Dekker et al., 2003) required to stimulate a change in state (e.g. after-ripening duration) (Dekker, et al., 1996; Dekker \& Hargrove, 2002; Sareini, 1970). Germination capacity is an inherent quality of a Setaria seed which is retained for its entire life.

The heteroblastic composition induced in an individual cohort of seeds is modulated by parental plant architecture and the environment during ca. 12 day embryogenic period. Earlier fertilized seeds produced on Setaria primary synflorescences (typically August in the midwest U.S.) are relatively more dormant than those from secondary synflorescences (ca. September), which are more dormant than seed on tertiary and subsequent synflorescences (ca. October) (Dekker, 2003).Hence, individual Setaria plant populations are most accurately defined as a unique combination of species, individual parent plant location and time of abscission (calendar Julian week (JW) and year).

Seed heteroblasty inevitably leads to formation of longlived seed pools in the soil. A seed pool begins with heterogeneous dormant seed dispersed into the soil from local or distant plants. The seed can remain dormant in the soil, after-ripen, germinate, emerge as a seedling, or die. Past soil seed pool studies have relied on population-based models (e.g. Bekker, et al, 2000; Hoffman, Owen \& Buhler, 1998; Roberts \& Nielson, 1981; Williams \& Harvey, 2002). Experimentally, they have described seed pools in terms of mean behaviours (e.g. number of seeds per unit area), vertical distribution, percent loss, species diversity, species richness, etc. These summary statistics obscure the individual behavioural patterns which underlie the population means, thus obscuring any relationship between the individual phenotype and its subsequent behaviour. Populationbased models are appropriate for quantifying differences among groups, but individually-based models are necessary to determine inferences of the relationship between heteroblasty and subsequent behaviour of a local population.

The relationship between seed dormancy capacity and subsequent behaviours has not been previously demonstrated. A fundamental question in plant seed biology concerns the ecological role of seed dormancy and the quantitative relationship between seed heteroblasty and recruitment timing: does dormancy capacity influence subsequent behaviour?

Therefore, the hypothesis for this series of articles is that heterogeneous germination requirements among S. faberi seed at abscission are a determinant of the subsequent behaviours of those individuals in the soil, including seedling recruitment timing. If seed heteroblasty can be quantified at abscission, can an empirical relationship between dormancy state at abscission and subsequent behaviours in the seed pool be shown? If so, the relationship between seed heteroblasty and subsequent behaviours may provide the hedgebet structure of seedling emergence timing. That is, heteroblasty is the "blueprint" for seedling recruitment. The heteroblastic differences among individuals of a specific population can be compared with other populations to reveal heterogeneous local adaptation across the landscape. These dormancy differences will be echoed in the pattern of seedling emergence, and evolve over time in their interaction with the changing environment.

The experimental goal for this first paper is to quantify the heterogeneity in germination capacity among S. faberi populations at abscission. Thus seed was gathered from S. faberi populations that differed primarily in location, year and calendar time of collection to determine how these factors were related to germination capacity. The germination capacity of a group of individual seeds can be determined by subjecting them to increasing durations of after-ripening signals and comparing differences in percent germination among populations. If there is local adaptation, each population will have a unique germination response to increasing after-ripening. But are there general patterns among locally adapted populations? To examine this possibility, populations were grouped on the basis of their germination capacity.

This paper characterizes the seed dormancy heterogeneity at abscission which is input into the soil. It is the first in a series of three papers on the dynamics of weedy Setaria soil seed pools. The second and third papers will examine seed in the soil and seedling emergence.

\section{Materials and Methods}

\subsection{Experimental}

\subsubsection{Setaria Populations}

For this study, a Setaria population was defined to be a specific combination of location and seasonal time of abscission (Table 1).Seeds collected from the same location but at different seasonal times were treated as samples from different populations rather than repeated measures of the same population. The sampled populations consisted of individual seeds, not the parent plants from which they werederived.Seeds developing early in the season differ from those developing later in the season due to the strong influence of photoperiod (Dekker, 2004; Dekker et al, 1996).

Locations. Two spatial criteria were used to select loca- 
tions from which $\mathrm{S}$. faberi seeds were collected. The primary criteria restricted populations to a local area around Ames, IA.Locations were all within $0^{\circ} 4{ }^{\prime} 77^{\prime \prime}$ latitude and $0^{\circ} 4$ '5" longitude of each other (Table 1). Most (Johnson, Curtiss, Oakwood, Wessex and Whiteoak) were less than $3 \mathrm{~km}$ from each other. The geographic range was restricted to allow characterization of a localized population phenotypic (heteroblastic) structure.A second criteria, used in 1999, was to collect from two distant locations in Iowa (near Crawfordsville, about $194 \mathrm{~km}$ from Ames) to gain some initial perspective on regional variation. All seed were gathered from almost pure Setaria monocultures, with special care taken to ensure no contamination from non-target Setaria species occurred. When seed was collected from the same site in different years the site was protected from human interference.

Seasonal time of abscission. Setaria seed development occurs continuously from July through November (Julian week (JW) 26-48) depending on environmental conditions. To evaluate the effects of time of abscission during this seed rain period, seed was collected at discrete intervals roughly corresponding to August (early; JW 31-35), September (middle; JW 35-39) and October (late; JW 40-44) (table 1). Our Julian week calendar assumes 29 days for every February.

\subsubsection{Seed Collection and Preparation}

The following standard procedures were repeated each year to supply genetically pure, mature, high quality seed for experimentation.

Seed collection. At the collection site, individual plants with mature synflorescences were identified by species. The seed heads were tapped against the wall of an empty plastic dishpan to dislodge the ripe seed. Ambient wind conditions in the field dislodge and disperse seeds from the parent plant soon after abscission (e.g., 0-5 days; Dekker et al., 1996). As such, the seed collected in these studies were recently abscised and represent the seed rain of that Julian week.

Table 1. Location (name, latitude, longitude) and nomenclature (lot no., name) of S. faberi populations grouped by year of abscission and collec-

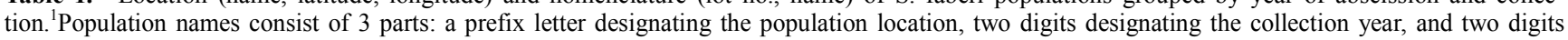
designating the Julian week of abscission and collection. All locations were in Ames, IA, except S.E. Research Station, near Crawfordsville, IA; R was $100 \mathrm{~m}$ west of Hinds $(\mathrm{H})$

\begin{tabular}{|c|c|c|c|c|c|}
\hline \multirow{2}{*}{ Name } & \multirow{2}{*}{$\underline{\text { Seed Collection Location }}$} & \multicolumn{4}{|c|}{ Population Nomenclature } \\
\hline & & Latitude & Longitude & Lot \# & Name $^{1}$ \\
\hline \multicolumn{6}{|l|}{1997} \\
\hline Curtiss Farm & $42^{\circ} 00^{\prime} 23 " \mathrm{~N}$ & $93^{\circ} 38^{\prime} 90^{\prime \prime} \mathrm{W}$ & & 3728 & C97-36 \\
\hline \multirow[t]{3}{*}{ Oakwood Drive } & $42^{\circ} 01^{\prime} 83^{\prime \prime} \mathrm{N}$ & $93^{\circ} 36^{\prime} 54^{\prime \prime W}$ & & 3732 & O97-34 \\
\hline & & & & 3733 & O97-36 \\
\hline & & & & 3734 & O97-37 \\
\hline \multicolumn{6}{|l|}{1998} \\
\hline \multirow[t]{3}{*}{ Curtiss Farm } & $42^{\circ} 00^{\prime} 23 " \mathrm{~N}$ & $93^{\circ} 38^{\prime} 90^{\prime \prime} \mathrm{W}$ & & 3740 & C98-32 \\
\hline & & & & 3746 & C98-36 \\
\hline & & & & 3754 & C $98-40$ \\
\hline \multirow[t]{4}{*}{ Hinds Farm } & & $42^{\circ} 03^{\prime} 65^{\prime \prime} \mathrm{N}$ & $93^{\circ} 36^{\prime} 96^{\prime \prime} \mathrm{W}$ & 3739 & H98-32 \\
\hline & & & & 3744 & R98-34 \\
\hline & & & & 3747 & H98-36 \\
\hline & & & & 3752 & $\mathrm{H} 98-40$ \\
\hline \multirow{3}{*}{ Johnson Farm } & $41^{\circ} 58^{\prime} 88^{\prime \prime} \mathrm{N}$ & $93^{\circ} 38^{\prime} 49^{\prime \prime} \mathrm{W}$ & & 3738 & J98-32 \\
\hline & & & & 3749 & J98-36 \\
\hline & & & & 3751 & $\mathrm{~J} 98-40$ \\
\hline \multirow{2}{*}{ Mortensen Road } & $42^{\circ} 00^{\prime} 57^{\prime \prime N}$ & $93^{\circ} 40^{\prime} 59^{\prime \prime} \mathrm{W}$ & & 3745 & M98-34 \\
\hline & & & & 3750 & M98-40 \\
\hline \multirow{2}{*}{ Wessex Road } & $41^{\circ} 59^{\prime} 67 " \mathrm{~N}$ & $93^{\circ} 38^{\prime} 30^{\prime \prime} \mathrm{W}$ & & 3743 & X98-34 \\
\hline & & & & 3758 & X98-39 \\
\hline \multirow{3}{*}{ Whiteoak Drive } & $41^{\circ} 59^{\prime} 75 " \mathrm{~N}$ & $93^{\circ} 38^{\prime} 90^{\prime \prime} \mathrm{W}$ & & 3741 & W98-32 \\
\hline & & & & 3748 & W98-36 \\
\hline & & & & 3753 & W98-40 \\
\hline \multicolumn{6}{|l|}{1999} \\
\hline \multirow[t]{3}{*}{ Curtiss Farm } & $42^{\circ} 00^{\prime} 23 " \mathrm{~N}$ & $93^{\circ} 38^{\prime} 90^{\prime \prime} \mathrm{W}$ & 3769C99-35 & & \\
\hline & & & 3770C99-38 & & \\
\hline & & & 3771C99-42 & & \\
\hline \multirow[t]{3}{*}{ Hinds Farm } & & $42^{\circ} 03^{\prime} 65^{\prime \prime} \mathrm{N}$ & $93^{\circ} 36^{\prime} 96^{\prime \prime} \mathrm{W}$ & \multirow{2}{*}{\multicolumn{2}{|c|}{ 3773H99-32 }} \\
\hline & & & 3774H99-36 & & \\
\hline & & & 3775H99-41 & & \\
\hline \multirow[t]{3}{*}{ Johnson Farm } & $41^{\circ} 58^{\prime} 88^{\prime \prime} \mathrm{N}$ & $93^{\circ} 38^{\prime} 49^{\prime \prime} \mathrm{W}$ & $3776 \mathrm{~J} 99-35$ & & \\
\hline & & & $3777 \mathrm{~J} 99-38$ & & \\
\hline & & & 3778J99-42 & & \\
\hline \multirow{3}{*}{$\begin{array}{l}\text { S.E. Research } \\
\text { Station }\end{array}$} & $41^{\circ} 12^{\prime} 36^{\prime \prime} \mathrm{N}$ & $91^{\circ} 29^{\prime} 73^{\prime \prime} \mathrm{W}$ & 3766B99-32 & & \\
\hline & & 3767B99-36 & & & \\
\hline & & & 3768B99-40 & & \\
\hline \multirow{3}{*}{$\begin{array}{l}\text { S.E. Research } \\
\text { Station }\end{array}$} & $41^{\circ} 12^{\prime} 26^{\prime \prime N}$ & $91^{\circ} 29^{\prime} 68^{\prime \prime} \mathrm{W}$ & 3779K99-32 & & \\
\hline & 3780K99-36 & & & & \\
\hline & & & $3781 \mathrm{~K} 99-40$ & & \\
\hline \multirow{3}{*}{ Whiteoak Drive } & $41^{\circ} 59^{\prime} 75^{\prime \prime} \mathrm{N}$ & $93^{\circ} 38^{\prime} 90^{\prime \prime W}$ & 3782W99-32 & & \\
\hline & & & 3783W99-36 & & \\
\hline & & & 3784W99-42 & & \\
\hline
\end{tabular}


Seed preparation.Seed lots were dried separately on \#16 (1.18 $\mathrm{mm}$ mesh openings) and or \#18 (1.00 mm openings) soil separation sieves (Seedburo Equipment Co., Chicago, IL, 60607) to allow adequate airflow around the seed while preventing any accidental mixing of different seed lots.Seed lots were dried at room temperature $\left(20^{\circ} \mathrm{C}\right)$ and ambient humidity for three to four days, stirred once per day. Once dry, the seeds were cleaned using a seed blower (Seedburo Equipment Co., Chicago, IL, 60607).This treatment removed any foreign particles leaving only hard, dark, mature seeds. The majority of these seeds were then used for dormancy and emergence experiments.A small portion of the seeds were placed into long-term storage at $-20^{\circ} \mathrm{C}$.

After-Ripening Germination Assays. Primary dormancy can be experimentally determined by exposing freshly abscised seeds to after-ripening (AR) conditions for various time intervals, then removing them to conditions optimal for germination. After-ripening germination assays were conducted in 1998 and 1999 on seed collected in 1997-1999. Seeds collected in 1998 and 1999 were evaluated immediately after harvesting and processing. Seeds collected 1997 were stored at $-20^{\circ} \mathrm{C}$, then removed from those conditions and tested at the same time as the 1998 populations. Past experience indicates storage for one year at $-20^{\circ} \mathrm{C}$ results in some low levels of after-ripening, but it is a small effect that does not change the relative differences between stored populations (Thornhill, 1997).This storage is an artefact to be considered in interpreting the results obtained from 1997 in subsequent dormancy and emergence experiments.

After-ripening environmental conditions. The general procedure for both years was as follows. A $60 \times 15 \mathrm{~mm}$ glass culture Petri dish (Fisher Scientific Company, Pittsburgh, PA, 15275) was labelled with the seed lot number and treatment. Two disks of Anchor Blue germination blotter paper (Anchor Paper Co., St. Paul, MN, 55101), 51mm in diameter, were placed in the dish completely covering the bottom. Immediately prior to sealing the dishes, $2 \mathrm{ml}$ (1998), or $3 \mathrm{ml}$ (1999) of distilled, de-ionized water was placed in the dishes along with 20 dry Setaria seeds. Preliminary studies showed similar germination responses over a wide range of water contents with dishes of this size (data not reported). The seeds were placed in a $5 \times 4$ grid on the germination paper to facilitate data collection. After arranging the seed, the dishes were immediately sealed by double-wrapping with Parafilm "M" ® (American National Can, Chicago, IL, 60631) to prevent water loss. Five replicates (Petri dishes) of each treatment were then doublewrapped with aluminium foil to ensure complete exclusion of light, and then placed in constant $4^{\circ} \mathrm{C}$ after-ripening conditions. In 1998, six treatments of 0-11 weeks of after-ripening $(0,14,35,49,63,77$ days $)$ were used. In 1999, 16 after-ripening treatments of $0-6.5$ weeks $(0,3,6,9,12$, $15,18,21,24,27,30,33,36,39,42,45$ days) were used.

Seed germination evaluation. After the specified after-ripening period the aluminium foil was removed, and the Petri dishes were placed into a controlled environment seed germination cabinet (Model SG-30, Hoffman Manufactur- ing, Inc., Albany, OR, 97321) for eight days. The daily conditions in the germination chamber alternated between 16 hours of light at $30^{\circ} \mathrm{C}$ followed by 8 hours of darkness at $20^{\circ} \mathrm{C}$. After eight days each dish was removed, opened, and evaluated for germination percentage. A seed was considered germinated if the coleorhiza and/or coleoptile protruded outside the seed hull.

\subsection{Analysis}

The focus of this study was to quantify the heterogeneity in germination capacity among Setaria populations which differ in the year, location, and seasonal time of seed collection. The effect of increasing after-ripening duration on percent seed germination was used to estimate the cumulative distribution of germination capacity within each individual population. Subsequent analysis was conducted to determine if there were general patterns of seed germination among populations in response to after-ripening duration.

\subsubsection{Germination Capacity Heterogeneity of Individual Populations}

Heterogeneity between years. The results from each year (1997, 1998, 1999) were analyzed separately because the locations and Julian weeks during which seeds were collected in 1997, 1998 and 1999 differed, though there was some overlap. Also, the after-ripening durations differed in the assays conducted in 1998 and 1999.Thus seed germination capacity of 1997, 1998 and 1999 populations could not be formally compared, except within two small subsets of the data. First, Curtiss in JW 36 was common to both 1997 and 1998.Percent germination from these two populations was analyzed using year, after-ripening duration, and their interaction as factors. Second, four populations (Hinds, Whiteoak in JW 32, 34) were common to both 1998 and 1999, and three after-ripening durations (1998:14, 35, 49 days; 1999:15, 36, 45 days) were similar. Percent germination from this subset was analyzed using ANOVA with year, location, seasonal time of abscission, after-ripening duration and their interactions as factors. The effect of year was tested using replication, plus the interaction of replication and year, as the error term. All other factors and interactions were tested using the residual error. The balanced design and residual plots indicated ANOVA was appropriate for these data. Separate analyses were then conducted for each of the three after-ripening durations.

Heterogeneity within years. Percent germination of populations collected within a year $(1997,1998,1999)$ were analyzed separately using ANOVA with duration of afterripening, population (a combination of location and seasonal time of abscission), and their interactions as factors. Percent germination from each after-ripening duration longer than 3 days was then analyzed separately (using one-way ANOVA), which allowed testing of mean separation using Tukey's multiple comparison tests. Data from 0 and 3 days of after-ripening were not analyzed as they consisted mostly of zeros and were thus not appropriate for 
ANOVA as indicated by their residual plots. Data from 6-77 days of after-ripening was appropriate for ANOVA as indicated by the balanced design, residual plots and the large number of seeds used ( 5 replications of 20 seeds for each of the 39 populations).

Heterogeneity within an after-ripening duration. The percent germination least squares means (LSmeans) for all populations within an after-ripening duration were compared using Tukey's multiple comparison tests. The relationship between germination and seasonal time of abscission was investigated using contrasts comparing seed collected during the early (JW 32), middle (JW36), and late (JW40-42) periods of the seed rain. Only those locations that had seed collected at all three times were included in these contrasts to avoid bias from location differences.

\subsubsection{General Patterns in Germination Capacity}

Patterns in population phenotypic structure of the Setaria seed evaluated herein were revealed at two, hierarchically linked levels of community organization: responses within individual populations to after-ripening duration and among populations across a varying landscape (local to regional).If general patterns exist, grouping individual populations with similar responses to after-ripening duration will provide a model of the population phenotypic structure at both levels. To accomplish this grouping, a clustering method was developed which began with ranking populations into groups within an after-ripening duration, then combined the results across durations to create a population grouping independent of after-ripening duration. Additionally, patterns among populations were utilized to link dormancy capacity and subsequent seedling emergence (Jovaag, Dekker \& Atchison 2009b).

Grouping of populations with similar phenotypic structures. A three part clustering method was developed to group populations. The first part, intra-AR grouping, ranked the populations into three groups based on the germination LSmeanswithin each after-ripening duration. The second part consisted of totalling each population's intra-AR rank numbers across durations. The third part, inter-AR grouping, was contingent on the intra-AR rank totals and created the final population grouping which was independent of after-ripening duration. A detailed description of this clustering method can be found in Jovaag (2006).

To reveal general patterns, the average percent germination within each after-ripening duration was calculated for each inter-AR group. The resulting curves were then smoothed using a degree three B-spline with two knots. Curves defined by the germination of individual populations were also smoothed to provide a schematic diagram of the relationship between after-ripening and germination.

The effectiveness of this clustering procedure was examined by simulating a dataset so that the actual inter-AR group of each population was known, then subjecting it to the clustering procedure to determine the proportion of populations that were correctly classified. To simulate the dataset, ten binomial random samples of size 100 were ob- tained using each average percent germination of the inter-AR groups (from the actual data).The proportion of successes from each of those samples was then used to obtain 5 binomial random samples of size 20.This resulted in a simulated dataset representing 5 replications of 20 seeds from 10 populations for each inter-AR group.

\section{Results}

\subsection{Germination Heterogeneity between Years}

Comparisons of S. faberi germination responses between years were made with the few populations (locations, Julian weeks) common to 1997-1998 and 1998-1999 seed. The germination response of 1997 and 1998 seed collected in the same location (Curtiss) and seasonal time (JW 36) depended on after-ripening (AR) duration (year*duration $\mathrm{p}$-value=.0012). In general, germination of 1997 seed tended to be greater than the 1998 seed at 35 days of AR, but the 1998 seed was more germinable with longer AR durations (49 and 77 days of AR). Germination of 1997 and 1998 seed was similar at 14 and 63 days of AR (Table 2). The germination response of the 1998 and 1999 seed collected in the same locations (Hinds and Whiteoak) and seasonal times (JW 32 and 36) depended on location, JW, and AR duration (year*location*JW*duration $\mathrm{p}<.0001$ ). In general, 1998 seed was more germinable than 1999 seed for three populations (Hinds JW32 and JW36, Whiteoak JW36) with AR durations of 35-36 and 45-49 days. Germination of 1998 and 1999 seed was similar for all four populations at 14-15 days of AR, and for the Whiteoak JW32 population at all AR durations (Table 2).

\subsection{Germination Heterogeneity within Years}

In all three years, after-ripening stimulated seed germination (ANOVA p-values <.0001). Generally, longer AR durations had higher germination than shorter durations (tables 3-5), but the effect of AR was not consistent for all populations (duration*population interactions, $\mathrm{p}<.0001$ ).

\subsubsection{7}

The least germinable 1997 population for most AR durations was Oakwood JW34 (O97-34) (Table 3). The most germinable populations for all AR durations were 097-36 and 097-37, which were similar to each other.Germination of the Curtiss JW36 population (C97-36) was intermediate to $097-34$ and $097-36 / 097-37$.

\subsubsection{8}

Germination differed among 1998 populations at all AR durations (all $\mathrm{p}<.0001$ ). The greatest range in germination occurred at 35 days AR when it varied from 9\% for C98-32 to $93 \%$ for X98-39 (Table 4).Germination ranking among populations within a single AR duration changed between durations, though W98-32 was often among the least germinable populations and M98-40 was often among the most 
germinable.

Seasonal time of abscission.Generally, in 1998, S. faberi seed collected early in the season was more dormant than seed collected in the middle of the season, which in turn was more dormant than seed collected late in the season. Differences in germination between these seasonal periods were significant (ANOVA contrasts) in most, but not all, cases (Table 6, top). The seed used for these contrasts was from the four locations (Curtiss, Hinds, Johnson, and Whiteoak) which had seed collected at a common time during all three periods (early, JW32; middle, JW36; late, JW 40).

Table 2. Comparison of 1997—1998 seed germination (Percent, least square mean) (top) and 1998 - 1999 seed germination (bottom) with after-ripening for the Curtiss (C97, C98) populations collected in Julian week (JW) 36 and the Hinds (H98, H99) and Whiteoak (W98, W99) populations collected in JW32 and JW36. Germination percentages within the same after-ripening duration with the same letter were not significantly different (probability $>.05$ )

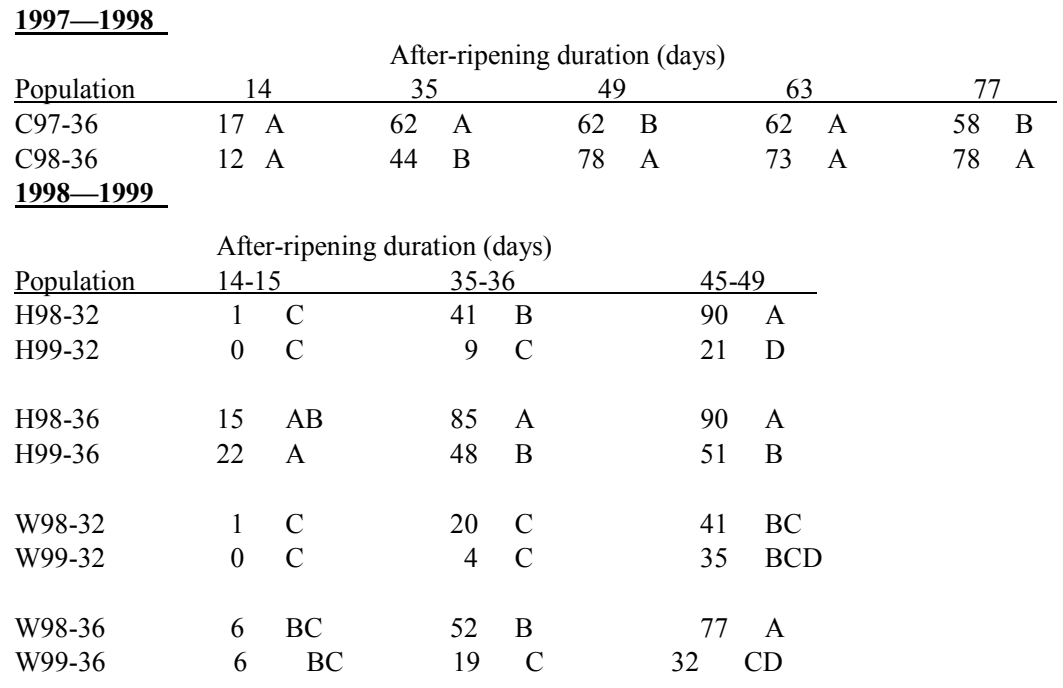

Table 3. Germination (percent seed germination, least square mean) of S. faberi seed populations collected in 1997 and evaluated in 1998 versus after-ripening duration. Populations: Curtiss farm (C97) and Oakwood drive (O97) populations collected during Julian weeks 34 (O97-34), 36 (C97-36; $\mathrm{O} 97-36)$ and 37 (O97-37). Germination percentages within the same after-ripening duration with the same letter were not significantly different (probability $>.05)$

\begin{tabular}{|c|c|c|c|c|c|c|c|c|c|}
\hline \multirow{3}{*}{$\frac{\text { Population }}{\text { C97-36 }}$} & \multicolumn{8}{|c|}{ After-ripening duration (days) } & \multirow[b]{2}{*}{77} \\
\hline & \multicolumn{2}{|c|}{14} & \multicolumn{2}{|c|}{35} & \multicolumn{2}{|c|}{49} & \multicolumn{2}{|c|}{63} & \\
\hline & & B & & A & 62 & B & 62 & $\mathrm{~A}$ & $58 \mathrm{~B}$ \\
\hline O97-34 & 10 & B & 33 & B & 30 & $\mathrm{C}$ & 27 & B & $39 \mathrm{~B}$ \\
\hline O97-36 & 40 & A & 74 & A & 90 & A & 82 & A & $82 \mathrm{~A}$ \\
\hline O97-37 & 53 & A & 75 & A & 77 & A & 70 & A & $81 \mathrm{~A}$ \\
\hline
\end{tabular}

Table 4. Germination ( ${ }^{1}$ percent seed germination, least square mean (LSMean)) of S. faberi collected in 1998 with after-ripening (AR) duration (days). Populations (see table 1 for full description) grouped by inter-AR group (see Methods \& Materials, Analysis): top, inter-AR group 1; middle, inter-AR group 2; bottom, inter-AR group 3. LSMeans within the same AR duration with the same letter were not significantly different (Tukey's test, probability $>.05)$

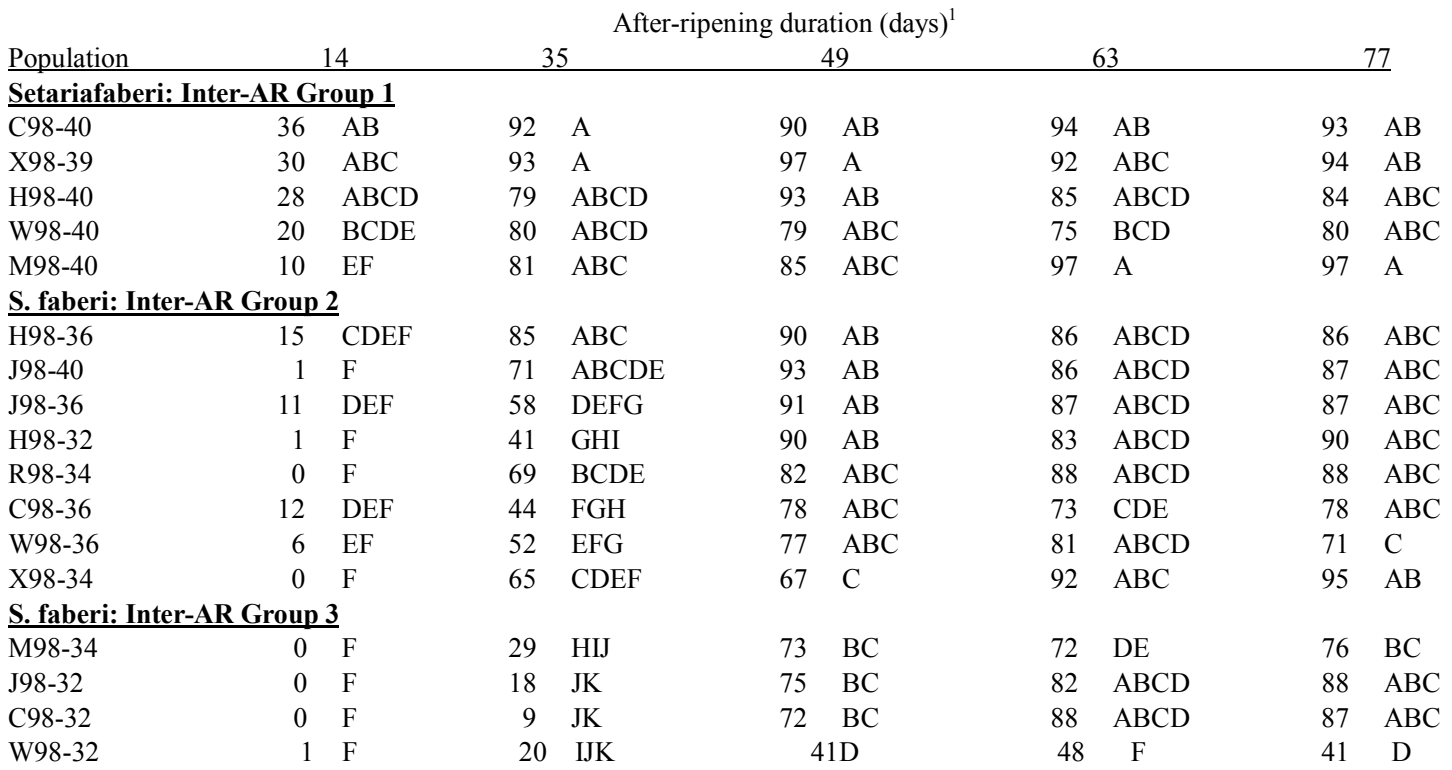


Table 5. Germination ( ${ }^{1}$ percent seed germination, least square mean) of $\mathrm{S}$. faberi collected in 1999 with after-ripening (AR) duration (days). Populations (see table 1 for full description) grouped by inter-AR group (see Methods \& Materials, Analysis): top, inter-AR group 1; middle top, inter-AR group 2; middle bottom, inter-AR group 3; bottom, inter-AR group 4; bottom. Means within the same AR duration with the same letter were not significantly different (Tukey’s test, probability>.05)

Part 1 (AR 6-24 d)

\begin{tabular}{|c|c|c|c|c|c|c|c|c|c|c|c|c|c|c|}
\hline \multirow[b]{2}{*}{ Population } & \multirow{2}{*}{\multicolumn{2}{|c|}{6}} & \multicolumn{6}{|c|}{ After-ripening Duration (days) ${ }^{1}$} & & \multirow{2}{*}{\multicolumn{2}{|c|}{21}} & \multirow{2}{*}{\multicolumn{2}{|c|}{24}} \\
\hline & & & \multicolumn{2}{|c|}{9} & \multicolumn{2}{|c|}{12} & \multicolumn{2}{|c|}{15} & & & & & & \\
\hline \multicolumn{11}{|c|}{ S. faberi: Inter-AR group 1} & & & \\
\hline B99-40 & 13 & $\mathrm{CDE}$ & 27 & $\mathrm{~B}$ & 31 & $\mathrm{AB}$ & 47 & A & 46 & A & 55 & A & 66 & A \\
\hline K99-40 & 19 & $\mathrm{BC}$ & 16 & $\mathrm{CDE}$ & 17 & $\mathrm{BCDE}$ & 26 & $\mathrm{~B}$ & 41 & $\mathrm{AB}$ & 47 & $\mathrm{AB}$ & 57 & A \\
\hline H99-41 & 41 & A & 46 & A & 45 & A & 52 & A & 45 & A & 59 & A & 53 & $\mathrm{AB}$ \\
\hline J99-42 & 13 & $\mathrm{CD}$ & 19 & $\mathrm{C}$ & 27 & $\mathrm{BC}$ & 24 & $\mathrm{~B}$ & 32 & $\mathrm{ABC}$ & 30 & $\mathrm{C}$ & 20 & DE \\
\hline W99-42 & & $\mathrm{AB}$ & 20 & $\mathrm{BCD}$ & 29 & $\mathrm{ABC}$ & 24 & B & 19 & $\mathrm{CDEF}$ & 23 & $\mathrm{CD}$ & 35 & $\mathrm{BCD}$ \\
\hline \multicolumn{15}{|c|}{ S. faberi: Inter-AR group 2} \\
\hline B99-36 & 2 & $\mathrm{DE}$ & 0 & $\mathrm{H}$ & 3 & $\mathrm{EF}$ & 6 & $\mathrm{CD}$ & 7 & DEFG & 15 & DEF & 23 & $\mathrm{CDE}$ \\
\hline C99-38 & & $\mathrm{CDE}$ & 10 & EFG & 7 & DEF & 11 & BCD & 11 & DEFG & 21 & $\mathrm{CDE}$ & 15 & $\mathrm{EF}$ \\
\hline C99-42 & 13 & $\mathrm{CDE}$ & 11 & DEF & 13 & CDEF & 25 & B & 23 & $\mathrm{BCD}$ & 32 & $\mathrm{BC}$ & 22 & $\mathrm{CDE}$ \\
\hline J99-38 & 2 & $\mathrm{DE}$ & 2 & FGH & 4 & $\mathrm{EF}$ & 3 & $\mathrm{D}$ & 1 & FG & 3 & $\mathrm{~F}$ & 0 & $\mathrm{~F}$ \\
\hline \multicolumn{15}{|c|}{ S. faberi: Inter-AR group 3} \\
\hline H99-36 & 5 & $\mathrm{DE}$ & 10 & EFG & 22 & $\mathrm{BCD}$ & 22 & $\mathrm{BC}$ & 20 & $\mathrm{CDE}$ & 35 & $\mathrm{BC}$ & 38 & $\mathrm{BC}$ \\
\hline \multicolumn{15}{|c|}{ S. faberi: Inter-AR group 4} \\
\hline$\overline{B 99-32}$ & 0 & $\mathrm{E}$ & 0 & $\mathrm{H}$ & 2 & $\mathrm{EF}$ & 0 & $\mathrm{D}$ & 2 & EFG & 5 & $\mathrm{EF}$ & 8 & $\mathrm{EF}$ \\
\hline K99-36 & 0 & E & 2 & FGH & 1 & $\mathrm{EF}$ & 3 & $\mathrm{D}$ & 5 & DEFG & 7 & DEF & 7 & $\mathrm{EF}$ \\
\hline K99-32 & 0 & $\mathrm{E}$ & 0 & $\mathrm{H}$ & 0 & $\mathrm{~F}$ & 0 & $\mathrm{D}$ & 0 & $\mathrm{G}$ & 1 & $\mathrm{~F}$ & 2 & $\mathrm{~F}$ \\
\hline W99-36 & 0 & E & 1 & $\mathrm{GH}$ & 1 & $\mathrm{EF}$ & 6 & $\mathrm{CD}$ & 11 & DEFG & 5 & $\mathrm{EF}$ & 10 & $\mathrm{EF}$ \\
\hline C99-35 & 0 & $\mathrm{E}$ & 0 & $\mathrm{H}$ & 0 & $\mathrm{~F}$ & 0 & $\mathrm{D}$ & 1 & FG & 5 & $\mathrm{EF}$ & 2 & $\mathrm{~F}$ \\
\hline W99-32 & 0 & E & 0 & $\mathrm{H}$ & 0 & $\mathrm{~F}$ & 0 & $\mathrm{D}$ & 0 & $\mathrm{G}$ & 0 & $\mathrm{~F}$ & 2 & $\mathrm{~F}$ \\
\hline J99-35 & 1 & E & 0 & $\mathrm{H}$ & 0 & $\mathrm{~F}$ & 0 & $\mathrm{D}$ & 0 & G & 2 & $\mathrm{~F}$ & 6 & $\mathrm{EF}$ \\
\hline H99-32 & 0 & $\mathrm{E}$ & 0 & $\mathrm{H}$ & 0 & $\mathrm{~F}$ & 0 & $\mathrm{D}$ & 0 & $\mathrm{G}$ & 2 & $\mathrm{~F}$ & 5 & $\mathrm{EF}$ \\
\hline
\end{tabular}

Part 2 (AR 27-45 d)

\begin{tabular}{|c|c|c|c|c|c|c|c|c|c|c|c|c|c|}
\hline \multicolumn{14}{|c|}{ After-ripening duration (days) ${ }^{1}$} \\
\hline Population & 27 & \multicolumn{2}{|c|}{30} & \multicolumn{2}{|c|}{33} & \multicolumn{2}{|c|}{36} & \multicolumn{2}{|c|}{39} & \multicolumn{2}{|c|}{42} & \multicolumn{2}{|c|}{45} \\
\hline \multicolumn{14}{|c|}{ S. faberi: Inter-AR group 1} \\
\hline$\overline{B 99-40}$ & $65 \mathrm{~A}$ & 72 & $\mathrm{~A}$ & 66 & $\mathrm{AB}$ & 70 & $\mathrm{AB}$ & 73 & $\mathrm{AB}$ & 78 & A & 65 & $\mathrm{AB}$ \\
\hline K99-40 & $61 \mathrm{AB}$ & 82 & A & 76 & A & 81 & A & 77 & A & 67 & $\mathrm{AB}$ & 35 & DEF \\
\hline H99-41 & $53 \mathrm{AB}$ & 48 & $\mathrm{BC}$ & 51 & $\mathrm{BCD}$ & 52 & $\mathrm{BCD}$ & 42 & CDEF & 49 & $\mathrm{BCDEF}$ & 44 & $\mathrm{CDE}$ \\
\hline $\mathrm{J} 99-42$ & 24 DEFG & 29 & CDEF & 28 & $\mathrm{EF}$ & 32 & $\mathrm{DEF}$ & 32 & EFGH & 32 & EFGH & 60 & $\mathrm{ABC}$ \\
\hline W99-42 & $27 \quad \mathrm{DE}$ & 40 & $\mathrm{CD}$ & 37 & $\mathrm{CDE}$ & 45 & $\mathrm{CDE}$ & 45 & $\mathrm{CDE}$ & 43 & CDEFG & 0 & $\mathrm{G}$ \\
\hline \multicolumn{14}{|c|}{ S. faberi: Inter-AR group 2} \\
\hline B99-36 & $34 \mathrm{CD}$ & 38 & $\mathrm{CDE}$ & 50 & $\mathrm{BCD}$ & 58 & $\mathrm{ABC}$ & 54 & $\mathrm{BC}$ & 56 & $\mathrm{ABCD}$ & 71 & A \\
\hline C99-38 & 23 DEFGH & 25 & CDEFG & 24 & EFGH & 32 & DEFG & 34 & DEFGH & 42 & CDEFG & 34 & DEF \\
\hline C $99-42$ & 23 DEFGH & 18 & DEFGH14 & $\mathrm{FG}$ & $\mathrm{HI}$ & 25 & EFGHI & 25 & FGH & 18 & HI & 16 & $\mathrm{FG}$ \\
\hline J99-38 & $5 \quad \mathrm{IJ}$ & 4 & $\mathrm{GH}$ & 24 & EFGH & 28 & DEFGH & 32 & DEFGH & 30 & EFGH & 30 & $\mathrm{EF}$ \\
\hline \multicolumn{14}{|c|}{ S. faberi: Inter-AR group 3} \\
\hline H99-36 & $47 \mathrm{BC}$ & 64 & $\mathrm{AB}$ & 56 & $\mathrm{ABC}$ & 48 & $\mathrm{BCDE}$ & 49 & $\mathrm{CD}$ & 59 & $\mathrm{ABC}$ & 51 & $\mathrm{ABCD}$ \\
\hline \multicolumn{14}{|c|}{ S. faberi: Inter-AR group 4} \\
\hline B99-32 & 25 DEFG & 19 & DEFGH30 & $\mathrm{DE}$ & EG & 32 & DEFG & 39 & CDEF & 34 & DEFGH & 45 & $\mathrm{BCDE}$ \\
\hline K99-36 & 11 FGHIJ & 16 & EFGH & 22 & EFGH & 26 & EFGH & 34 & DEFGH & 52 & $\mathrm{BCDE}$ & 70 & A \\
\hline K99-32 & $1 \mathrm{~J}$ & 2 & $\mathrm{GH}$ & 13 & FGHI & 10 & GHI & 25 & FGH & 32 & EFGH & 68 & A \\
\hline W99-36 & 11 FGHIJ & 10 & FGH & 16 & EFGHI & 19 & FGHI & 34 & DEFGH & 25 & $\mathrm{GH}$ & 33 & DEF \\
\hline C99-35 & 15 EFGHIJ & 7 & $\mathrm{GH}$ & 14 & FGHI & 16 & FGHI & 28 & EFGH & 26 & FGH & 22 & $\mathrm{~F}$ \\
\hline W99-32 & $1 \mathrm{~J}$ & 5 & $\mathrm{GH}$ & 7 & $\mathrm{HI}$ & 4 & HI & 19 & GHI & 28 & FGH & 32 & DEF \\
\hline J99-35 & 10 GHIJ & 10 & FGH & 9 & GHI & 15 & FGHI & 19 & GHI & 28 & FGH & 22 & $\mathrm{~F}$ \\
\hline H99-32 & 9 HIJ & 7 & GH & 10 & FGHI & 9 & GHI & 16 & $\mathrm{HI}$ & 15 & $\mathrm{HI}$ & 21 & $\mathrm{~F}$ \\
\hline
\end{tabular}

\subsubsection{9}

Germination differed among 1999 populations at all AR durations (all $\mathrm{p}<.0001)$. The greatest range in germination occurred at 30 days of AR where average germination ranged from $2 \%$ for $\mathrm{K} 99-32$ to $82 \%$ for K99-40 (table 5).Germination ranking among populations within a single AR duration changed between AR durations, though H99-32 was often among the least germinable populations and the SE Research Station (JW40) was often among the most germinable.

Seasonal time of abscission. In 1999, the same 1998 seasonal pattern of increasing germinability was observed: S. faberi seed collected early in the season was more dormant than seed collected in the middle of the season, which in turn was more dormant than seed collected late in the season. Differences in germination between these seasonal periods were significant (ANOVA contrasts) in most, but not all, cases (table 6, bottom). The seed used for these contrasts was from the four locations (Hinds, SE Research sta- 
tion sites $1 \& 2$, and Whiteoak) which had seed collected at a common time during all three periods (early, JW32; middle, JW36; late, JW 40).

Regional variation. Germination of the Crawfordsville populations was within the range of the Ames populations (Table 5) for shorter AR durations. With longer AR durations, the Crawfordsville populations, especially those from the latest seasonal collection dates (B99-40 and K99-40), were among the least dormant 1999 populations.

\subsection{General Patterns in Germination}

Patterns in germination heterogeneity among populations were evaluated by ranking the populations into inter-AR groups. The clustering procedure used to obtain these inter-AR groups was effective.For the simulated data, it correctly classified $80 \%$ (simulated 1998 data) to $93 \%$ (simulated 1999 data) of the populations.

\subsubsection{Patterns across AR Durations (Inter-AR Groups)}

Three basic germination patterns in response to increasing after-ripening were revealed by inter-AR grouping. The first pattern was a rapid increase in germinability at the shorter durations then remaining steadily high at longer durations, the second was a relatively consistent increase in germinability as duration increased, and the third was little or no early germination but a rapid increase with longer durations.

1998. Generally, the mean germination for 1998 inter-AR groups 1 and 2 show a rapid increase at the shorter durations, then steady, high germination at the longer durations (Figure 1, top right). The amount of germination was greater in group 1 than in group 2 at the shorter durations, then similar at the longer durations. Germination in group 3 increased at a relatively slower rate with increasing after-ripening duration compared to groups 1 and 2, and was also less germinable.

1999.Generally, mean germination for 1999 inter-AR groups 1 and 2 showed a relatively constant increase for the first 36 days of AR, then remained steady with increasing after-ripening duration (Figure 1, bottom right), but the amount of germination was higher in group 1 than in group 2 at all AR periods. Mean germination for the most dormant group (4), was very low at first, then began to increase with longer after-ripening durations. Group 3 contained only one population (H99-36), but its pattern was different from the other groups, and thus is presented separately (table 5). Mean germination for H99-36 started out lower than in groups 1 and 2, but had a greater rate of increase in germination in response to AR for the first 35 days of AR.

The germination pattern for seasonal time of abscission (increasing germinability from early to late) was also observed in the 1998 and 1999 inter-AR groups, e.g., H99$32 / 36 / 41$. Populations collected late in the season tended to be in group 1 (the most germinable group for both years). Populations collected in the middle of the season tended to be in group 2 in 1998 and groups 2 or 3 in 1999.Populations collected early in the season tended to be in group 3 in 1998 or group 4 in 1999 (the least germinable groups).In all seasonal periods there were exceptions (Tables 4-5).

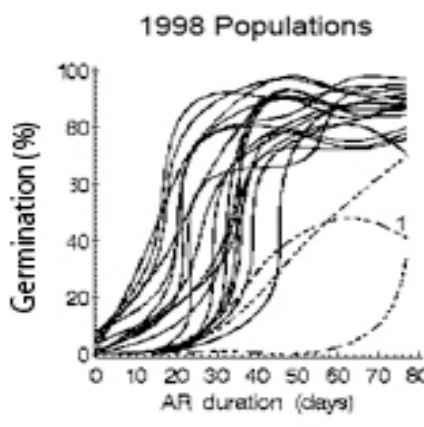

1998 Population Groups
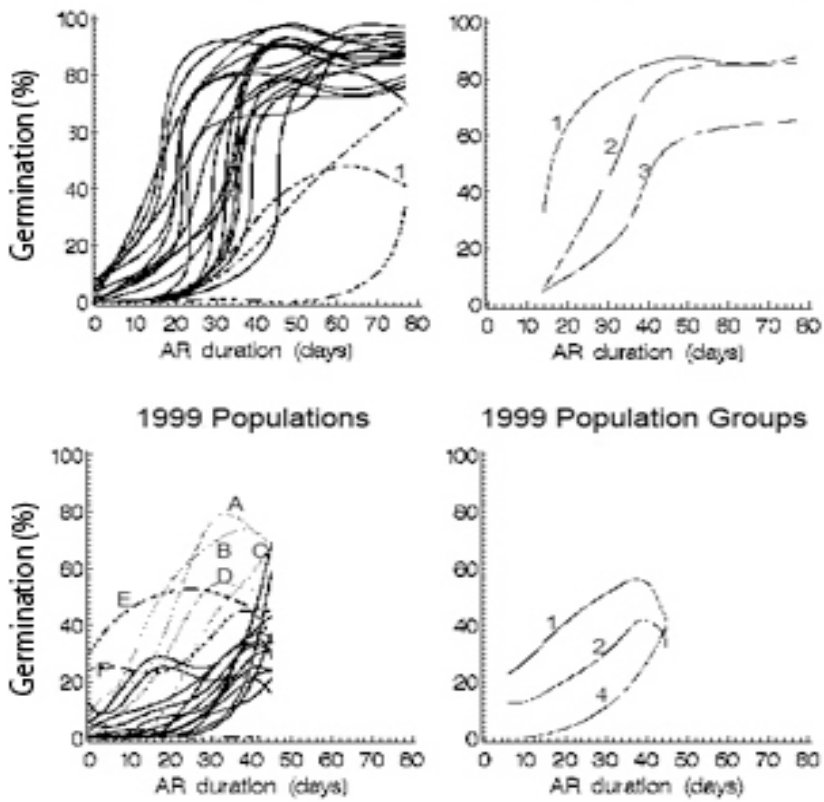

1999 Population Groups

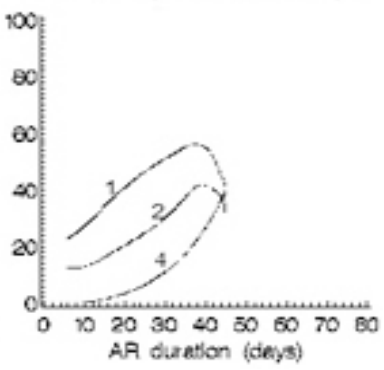

Figure 1. Germination (percent seed germination, least square mean, smoothed curves) versus after-ripening (AR) duration (days) for all individual 1998 (top left) and 1999 populations (bottom left), and for the 1998 (top right) and 1999 (bottom right) inter-AR groups (See tables 4-5 for populations included in each inter-AR group). Individual populations with unusual patterns are shown as dashed lines; 1: W98-32, A: K99-40, B: B99-40, C: B99-36, D: H99-36, E: H99-41, F: W99-42. Line numbers in the group plots are the inter-AR group numbers. Group 3, 1999, is not shown in the bottom right plot as it consists of a single population-H99-36, line D, lower left

Table 6. Difference in S. faberi germination (percent germination, least square mean) among populations collected during the early (Julian week (JW) 32), middle (JW36) and late (JW40) seasonal periods of the seed rain in 1998 and 1999 with after-ripening (1998: 14-77 days; 1999: 6-45 days). Populations used: 1998, Curtiss, Hinds, Johnson, and Whiteoak; 1999, Hinds, SE Research station sites $1 \& 2$, and Whiteoak. ${ }^{1}$ NS $=$ no significant difference (ANOVA contrast, probability $(\mathrm{p})>.05), *=.01<\mathrm{p}<.05, * *=.001<\mathrm{p}<.01, * * *=\mathrm{p}<.001$

\section{$\underline{1998}$}

\begin{tabular}{|c|c|c|}
\hline 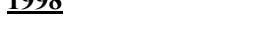 & After-rip & Duration (days) ${ }^{1}$ \\
\hline Contrast & 14 & 35 \\
\hline Early - Middle & $-10.5 * * *$ & $-37.8 * * *$ \\
\hline Early - Late $-20.8 * * *$ & $-58.6 * * *$ & $-19.3 * * *$ \\
\hline Middle - Late & $-10.3 * * *$ & $-20.9 * * *$ \\
\hline
\end{tabular}

1999
Contrast

Early - Middle

Early - Late $-25.3 * * *$

Middle - Late
After-ripening Duration (days) ${ }^{1}$

$\begin{array}{ccccccc}6 & 15 & 21 & 27 & 36 & 42 & 45 \\ -1.8^{\mathrm{NS}} & -9.3^{* * *} & -13.4^{* * *} & -16.8^{* * *} & -23.8^{* * *} & -20.8^{* * *} & -15.3^{* * *} \\ -37.1^{* * *} & -44.0^{* * *} & -42.5^{* * *} & -48.3^{* * *} & -32.0^{* * *} & -12.8^{* * *} & \\ -23.5^{* * *} & -27.9 * * * & -30.6^{* * *} & -25.8^{* * *} & -24.4^{* * *} & -11.3^{* * *} & 2.5^{\mathrm{NS}}\end{array}$




\section{Discussion}

"Clines in seed polymorphism...may be a most sensitive indicator of evolution in weedy species." "it is in properties such as seed number, seed size, seed polymorphisms, and precise germination requirements that the most sensitive reactions of a species to an alien environment are likely to occur." (Harper, 1965).

Characterizing Setaria seed dormancy polymorphisms, both within and between populations, and the phenotype space they occupy, are important steps in understanding precisely how a species responds directly to, and evolves over time within, its local environment. For Setaria, considerable heterogeneity in germination requirements existed among and within all populations tested. Year, seasonal time of abscission, and location all proved to be important factors influencing the germination heterogeneity structure of Setaria populations as revealed by after-ripening. These observed heteroblastic differences within and among populations revealed a fine scale adaptation to local space and time conditions.

Generally, germination increased with increasing after-ripening duration (Figure 1). The pattern of increasing germination with increasing AR durations contained more noise for the 1999 populations than for the 1997 and 1998 populations because the AR durations were much closer together, thus the variability among seeds from a single population was more easily observed.

The observed differences between years (1997 seed more germinable than 1998 seed at short AR durations, 1997 seed less germinable than 1998 seed at longer AR durations, 1998 seed more germinable than 1999 seed) were not surprising since differing conditions experienced during embryogenesis in different years stimulate different ranges of germination capacities (Dekker et al. 1996; Dekker 2003, 2004).However, only a limited amount of data was available to test these differences, so the results may not be representative of all populations.

Earlier harvested seed was consistently less germinable than later harvested seed. This is consistent with earlier studies (Dekker, 2004; Dekker et al, 1996) suggesting the importance of photoperiod, which is longest while the early (JW32-August) seeds are developing, then decreases through the middle (JW36-September) and late (JW40October) periods of the seed rain.

There were some regional differences (Ames versus Crawfordsville) in germination for the $1999 \mathrm{~S}$. faberi populations. Crawfordsville populations tended to be among the most germinable populations at longer AR durations, but not at the shorter durations (e.g. lines A-C in Figure 1).At the local field scale, within either Ames or Crawfordsville, there was no clear pattern to the observed differences in germinability among locations. Differences in the heteroblastic structure among locations within either region were complex and likely a consequence of numerous environmental, climatic and cropping system factors interacting at the micro-site scale. This complexity in heteroblasty among locations was not amenable to simple pattern differentiation.

\subsection{General Germination Patterns}

General patterns in heteroblastic structure were observed within and among populations ranked in intra- and inter-AR groupings that encompass the parameters above (year, seasonal time of abscission, location, species, light). Observed responses of seeds to after-ripening graphically represent the regions within which seeds did and did not germinate. Those regions can then be used to visualize the phenotype space within which these general patterns could be more readily characterized. A schematic diagram of this generalized phenotype space is given in Figure 2.

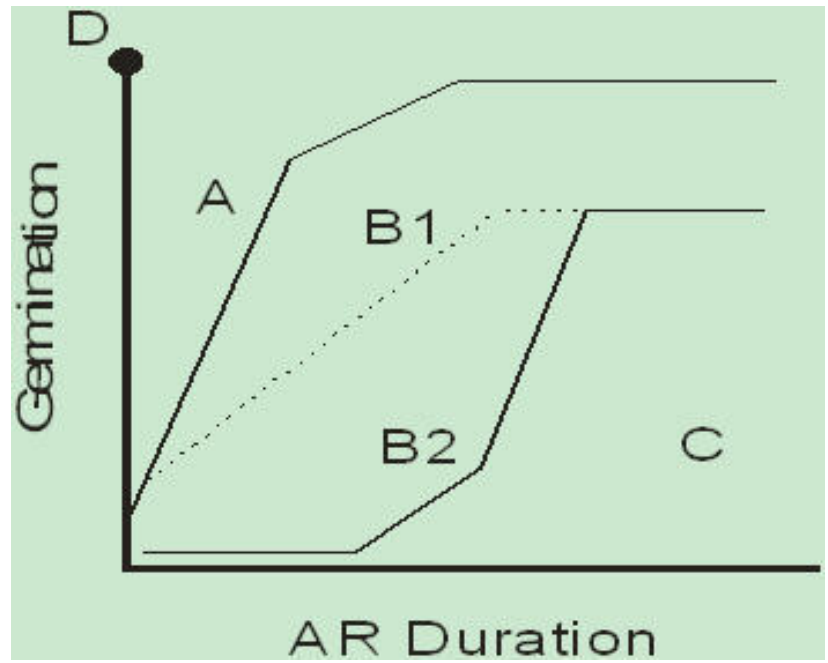

Figure 2. Schematic diagram of the hedge-bet structure within the heteroblasty phenotype space. A: High initial germinability, rapid germination response to after-ripening (AR). B1: Low initial germinability, increasing germinability with increasing AR duration until a plateau of high germinability is reached. B2: Increasing germinability with increasing AR, but less overall germination than in B1. C: Little or no early germinability, but some increase with long AR durations. D: "Perfect" crop response-all seeds immediately germinable

The most commonly occupied phenotype space occurred within the $\mathrm{B} 1$ and $\mathrm{B} 2$ regions (Figure 2). These regions defined a pattern of low $(<10 \%)$ initial germination, then increasing germination with increasing $\mathrm{AR}$, followed by a plateau at about 40-50 days of after-ripening when the germination response to added after-ripening was saturated (at $70-100 \%$ germination). The majority of the 1998 populations occupied the B1 and B2 regions, while most 1999 populations occurred only in the B2 region (figure 2, upper and lower left, solid lines).Thus the 1998 populations tended to have a more rapid response to increased after-ripening (10-40 day period) than the 1999 populations. However, there were four populations in 1999 (Figure 1, lower left, lines A-D) that had a more rapid response to after-ripening compared to the other 1999 populations, and were similar to the 1998 populations.

Inter-AR groupings reveal the general trends in germination response to after-ripening, although some detail is lost when the most common patterns are combined with those 
less frequently observed.These generalized inter-AR functions provide a comprehensive view of modal patterns within the heteroblastic phenotype space for all the S. faberi populations evaluated. Smoothed functions emphasized seed responded more quickly to after-ripening in 1998 than in 1999 (response of groups 1 and 2 in 1998 greater than groups 1 and 2 in 1999, respectively).The least germinable populations (group 3 in 1998, group 4 in 1999) had similar responses to after-ripening in both years (Figure 1, upper and lower right).

Other phenotype spaces, namely regions A (high initial germination, rapid response to after-ripening) and $\mathrm{C}$ (low or no initial germination, slow response to after-ripening) were less commonly occupied than the B1/B2 regions. Phenotype region $\mathrm{C}$ in 1998 was occupied by two $\mathrm{S}$. faberi populations, X98-34-S (Figure 1, top left, line 1) and W98-32 (line 2), both with unusually high dormancy in the second half of their distributions. Phenotype region A in 1999 was occupied by two populations, H99-41 (Figure 1, bottom left, line E) and W99-42 (line F) with high germination in the beginning of their distributions (0-6 or 9 days AR, table 5). Region A also contains the ideal crop response (fully germinable with no after-ripening needed, point $\mathrm{D}$, Figure 2).

These studies emphasize the crucial role that environment (year, season) at the time of seed formation and embryogenesis plays in the dormancy phenotype produced by plants in a locality. The location itself (soil properties, fertility, past management history, etc.), the 'terroir', can also influence the quality of plant phenotypes produced. The role of locality per se is apparent in the phenotypes produced at Whiteoak which occupied region C in 1998 (W98-32) and A in 1999 (W99-42). Whiteoak as a locality interacted with its local genotype(s) to produce phenotypes in these two atypical populations which accentuated the opposite trend in germinability for that year's climate. In a low dormancy year (1998), the early (typically the most dormant) cohort produced seed with unusually high dormancy. In a low germinability year (1999), the late (typically the most germinable) cohort produced seed with unusually high germinability.

The germination patterns observed and dormancy phenotype space occupied, defined the heteroblastic hedge-bet structure at abscission. The B1/B2 regions were the most commonly occupied phenotype spaces, suggesting a population's "best bet" generally laid within this region. Variation among populations within this region indicated a fine scale adaptation to the local environment. Regions A and C were less commonly occupied, suggesting they were "long shots" at the edge of local adaptation. Populations may occupy these regions in response to locality, year and seasonal effects (e.g., Whiteoak). What bets were realized from this heteroblasty, that is, the subsequent seed fates including germination and emergence in the field, are revealed in the next two papers in this series (Jovaag, Dekker \& Atchison, 2009a, b).

\section{REFERENCES}

[1] Baloch A, DiTommasoA\& Watson AK (2001) Intrapopulation variation in Abutilon theophrasti seed mass and its relationship to seed germinability. Seed Science Research 11, 335-343

[2] Bekker RM, Verweij GL, Bakker JP \& Fresco LFM (2000) Soil seed bank dynamics in hayfield succession. Journal of Ecology 88, 594-607

[3] Chambers JC (1995) Disturbance, life history strategies, and seed fates in alpine herbfield communities.American Journal of Botany 82(3), 421-433

[4] Dekker J (2004) The evolutionary biology of the foxtail (Setaria) species-group.In: Weed Biology and Management. (ed. Inderjit).Kluwer Academic Publishers, The Netherlands, 65-113

[5] Dekker J (2003) The foxtail (Setaria) species-group.Weed Science 51, 641-646

[6] Dekker J, Atchison B, Jovaag K (2003) Setaria spp. seed pool formation and initial assembly in agro-communities. Aspects of Applied Biology 69, 247-259

[7] Dekker J \& Hargrove M (2002) Weedy adaptation in Setaria spp.: V. Effects of gaseous atmosphere on giant foxtail (Setariafaberi) (Gramineae) seed germination.American Journal of Botany 89, 410-416

[8] Dekker J, Luschei E \& Buhler D (1999) Autumnal germination phenotype predicts giant foxtail (Setariafaberi) seedling emergence.6th International Workshop on Seeds, Merida, Yucatan, Mexico

[9] Dekker J, Dekker BI, Hilhorst H \&Karssen C (1996) Weedy adaptation in Setariaspp: IV.Changes in the germinative capacity of S. faberi embryos with development from anthesis to after abscission.American Journal of Botany 83(8), 979-991

[10] Forcella F, Wilson RG, Dekker J et al. (1997) Weed seed bank emergence across the corn belt.Weed Science 45, 67-76

[11] Forcella F, Benech-Arnold RL, Sanchez R \&Ghersa CM (2000) Modeling Seedling Emergence.Field Crops Research 67, 123-139

[12] Gutterman Y, (1996) Environmental influences during seed maturation and storgage affecting germinability in Spergulariadiandraga genotypes inhabiting the Negev Desert, Israel. Journal of Arid Environments 34, 313-323

[13] Harper JL (1965) Establishment, Aggression, and cohabitation in weedy species.In: The Genetics of Colonizing Species.(eds. HG Baker \& GL Stebbins), 243-265. Academic Press, New York, USA

[14] HaAr JM (1998) Characterization of foxtail (Seraria spp.) seed production and giant foxtail (Setariafaberi) seed dormancy at abscission.PhD thesis, Iowa State University, Ames, Iowa, USA

[15] Hoffman ML, Owen MDK \& Buhler DD (1998) Effects of Crop and Weed Management on Density and Vertical distribution of weed seeds in soil. Agronomy Journal 90, 793:799

[16] Jones CS (1999) An essay on juvenility, phase change, and heteroblasty in seed plants. International Journal of Plant 
Science 160, 5105-5111

[17] Jovaag K (2006) Life History of Weedy Setaria species-group.PhD thesis, Iowa State University, Ames, Iowa, USA

[18] Roberts HA \& Neilson JE (1981) Changes in the soil seed bank of four long-term crop/herbicide experiments.Journal of Applied Ecology 18, 661-668

[19] Rogers WE \& Hartnett DC (2001) Temporal vegetation dynamics and recolonization mechanisms on different-sized soil disturbances in tallgrass prairie.American Journal of Botany 88(9), 1634-1642

[20] Rost TL \&Lersten NR (1970) Transfer aleurone cells in Setarialutescens (Gramineae).Protoplasma 71, 403-408

[21] SareiniHT (2002) Identification and characterization of the major seed peroxidase in Setariafaberi.MS thesis, Iowa State University, Ames, Iowa, USA

[22] Thompson K \& Grime JP (1979) Seasonal variation in the seed banks of herbaceous species in ten contrasting habitats.Journal of Ecology 66, 893-921

[23] Thornhill RG (1997) The effect of temperature and moisture on germination of giant foxtail (Setariafaberi) seeds, caryopses and embryos.MS thesis, Iowa State University, Ames,
Iowa, USA

[24] Thurston JM (1957) Morphological and physiological variation in wild oats (Avenafatua L. and A. ludovicianaDur.) and in hybrids between wild and cultivated oats.Journal of Agricultural Science, Camb. 49, 260-274

[25] Trewavas AJ (1987) Timing and memory processes in seed embryo dormancy-A conceptual paradigm for plant development questions.BioEssays 6(2), 87-92

[26] Wang RL, Wendell J \& Dekker J (1995) Weedy adaptation in Setaria spp.: II. Genetic diversity and population genetic structure in S. glauca, S. geniculata and S. faberi. American Journal of Botany 82(8), 1031-1039

[27] Weaver SE \&Lechowicz MJ (1983) Biology of Canadian weeds.56.Xanthium strumarium L.Cocklebur.Canadian Journal of Plant Science 63, 211-225

[28] Williams JT \& Harper JL (1965) Seed polymorphism and germination.1.The influence of nitrates and low temperatures on the germination of Chenopodium album. Weed Research 5, 141-150

[29] Williams BJ \& Harvey RG (2002) Influence of simulated seed rain on the seed bank of wild-proso millet. Weed Science $50,340-343$ 